\title{
Correlation between liver volume and liver weight in a cohort with chronic liver disease: a semiautomated CT-volumetry study
}

\author{
Florian Hagen $^{1 \wedge}$, Antonia Mair ${ }^{1} \wedge$, Hans Bösmüller ${ }^{2 \#}$, Marius Horger $^{1 \# \wedge}$ \\ ${ }^{1}$ Department of Diagnostic and Interventional Radiology, Eberhard-Karls-University, Tübingen, Germany; ${ }^{2}$ Department of Pathology and \\ Neuropathology, Eberhard-Karls-University, Tübingen, Germany
}

Contributions: (I) Conception and design: M Horger, F Hagen; (II) Administrative support: M Horger; (III) Provision of study materials or patients: M Horger; (IV) Collection and assembly of data: F Hagen, A Mair; (V) Data analysis and interpretation: F Hagen, A Mair, M Horger; (VI) Manuscript writing: All authors; (VII) Final approval of manuscript: All authors.

"These authors contributed equally to this work.

Correspondence to: Florian Hagen. Department of Diagnostic and Interventional Radiology, Eberhard-Karls-University, Hoppe-Seyler-Str. 3 , 72076 Tübingen, Germany. Email: florian.hagen@med.uni-tuebingen.de.

Background: To estimate the optimal density coefficient for conversion of liver volume into liver weight in patients with chronic liver disease based on semiautomated CT-liver volumetry data and the histologic Ishak score of explanted liver.

Methods: A total of 114 patients (39 female; age, 46 \pm 20 years) with chronic liver diseases who underwent liver transplantation between January 2010 and September 2020 were identified over a patient chart search at our institution and subsequently analyzed in retrospect. All patients had contrast-enhanced CT-examinations (mean, 24 days) to liver transplantation. Liver volume was calculated by a semiautomated software and results compared with the liver weight registered by the pathologist. Each explanted liver was histologically scored into six classes according to the Ishak classification where the categories were subgrouped based on recommendation of the pathologists into the following categories 0-3, 4-5 and 6.

Results: Mean liver volume was $1,870 \pm 1,195,1,162 \pm 679$ and $1,278 \pm 510 \mathrm{~mL}$ for the categories $0-3,4-5$ and 6, respectively. Mean liver weight was $1,624 \pm 999,1,082 \pm 669$ and 1,346 $\pm 559 \mathrm{~g}$ for the categories $0-3$, $4-5$ and 6, respectively. A coefficient of $0.92 \pm 0.22,0.98 \pm 0.28$ and $1.06 \pm 0.20 \mathrm{~g} / \mathrm{mL}$ was found at best for conversion of liver volume into liver weight in these subgroups. Differences between Ishak-subgroups proved significant (0.002). In 4 patients with cystic liver disease, density coefficients varied significantly and were found generally lower compared to the other liver disorders.

Conclusions: Our results yielded significant differences between the density coefficients calculated along with the Ishak score and also for the subgroup with cystic liver disease.

Keywords: Liver volume; syngo-via liver analysis; liver transplantation

Submitted Mar 17, 2021. Accepted for publication Jun 15, 2021.

doi: 10.21037/qims-21-299

View this article at: https://dx.doi.org/10.21037/qims-21-299

^ ORCID: Florian Hagen, 0000-0002-1215-9428; Antonia Mair, 0000-0002-7205-2657; Hans Bösmüller, 0000-0002-7515-435X; Marius Horger, 0000-0003-3744-5479. 


\section{Introduction}

Accurate quantification of the liver volume and weight is a prerequisite for liver resection and transplantation (1-3), for avoiding metabolic mismatches between donor and recipient which may result in "small-for-size syndrome" or "large-for-size syndrome" and ultimately in an increased risk of graft rejection (4). In the past, surrogate variables to determine metabolic mismatches, such as the donor height to recipient height ratio (5) as well as formulas calculating the liver weight based on age, gender and body weight (6) led to controversial results. For this reason, preoperative CT-volumetry is frequently performed in clinical practice (7). Besides manual, time-consuming techniques, semiautomated reliable volume assessment techniques have emerged which are based on complex segmentation, organ surface, and structure (e.g., vessel) recognition algorithms (8-10). The most accurate method for liver volume quantification is ex-vivo by measuring either the displaced water volume of the explanted organ or by weighting e.g., the liver $(11,12)$. However, a metabolic mismatch can also be caused by an excessive weight difference (3), which can be attributed to the varying liver consistency among patients mainly due to the underlying disorder and its grade (13-15). These coefficient factors have been evaluated in different clinical settings both in patients with normal livers as well as in such with chronic liver diseases $(16,17)$. Most of them, however, have been calculated globally for all liver disorders without any further differentiation of disease stage, cause, etc. $(16,18)$.

Hence, the intention of this study was to assess the optimal coefficient factors for conversion of liver volume into liver weight and vice versa differentiating between stages of liver diseases with distinct histologic features.

\section{Methods}

\section{Patient characteristics}

This retrospective data evaluation was approved by the institutional review board which was assigned the approval number $841 / 2020 \mathrm{BO} 2$. The study was conducted in accordance with the Declaration of Helsinki (as revised in 2013). Verbal and written informed consent was waived due to the retrospective nature of the study.

A total of 550 Patients underwent liver transplantation between January 2010 and September 2020 at University Hospital of Tübingen. A total of 300 patients were excluded from the study due to the missing cross-sectional CT-

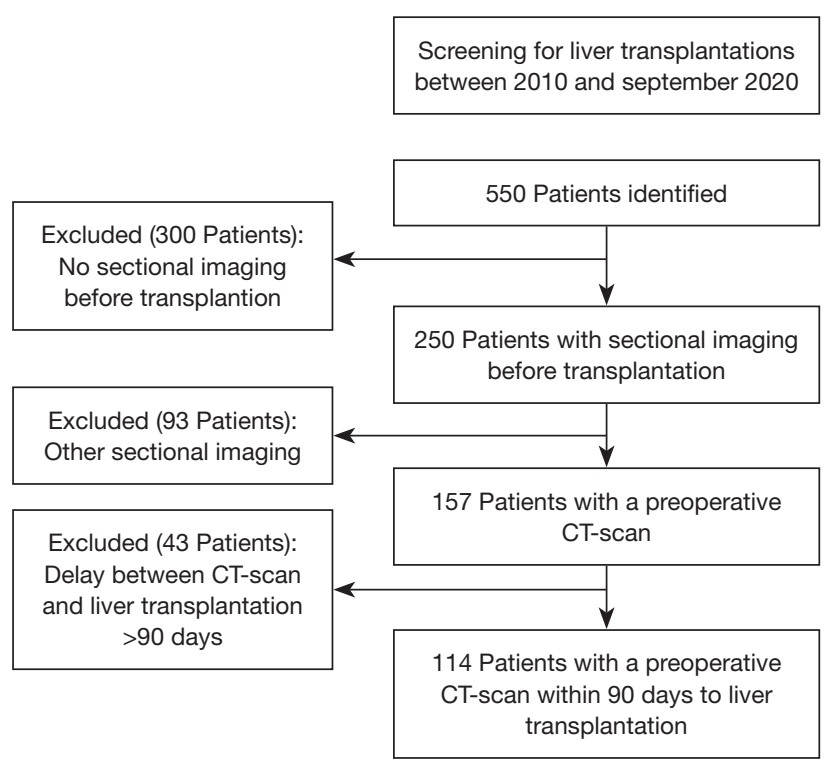

Figure 1 Study population.

imaging. Finally, 114 patients who had comparable CT-scan image data [thin-slice (1 mm or less), contrast-enhanced studies] were included (Figure 1).

\section{CT-examinational protocol}

CT-examinations were all performed on a multi-slice CTscanner (Siemens Definition 16/AS+/Flash and/or Force, Forchheim, Germany). Only comparable CT-examinations including a portal venous phase were considered. The delay between injection of the contrast agent and the scan was about 65 seconds. The time interval between CT-imaging and liver explantation was mean, $24 \pm 26$ days (range, $0-90$ days).

\section{CT-imaging data analysis}

All image data were transferred to the syngo.via server (VB 30) for post-processing with a dedicated liver analysis application (syngo.CT Liver Analysis). Due to the poor differences of about $1-2 \mathrm{~mL}$ in total liver volume between inclusion of liver vessels of 3 or $15 \mathrm{~mm}$, we opted for the widest range of vessel inclusion $(15 \mathrm{~mm})$.

\section{Automated liver measurements}

The main steps in the calculation of automated liver volumes are shown by the chart below (Figure 2).

For pose detection the marginal space learning (MSL) 


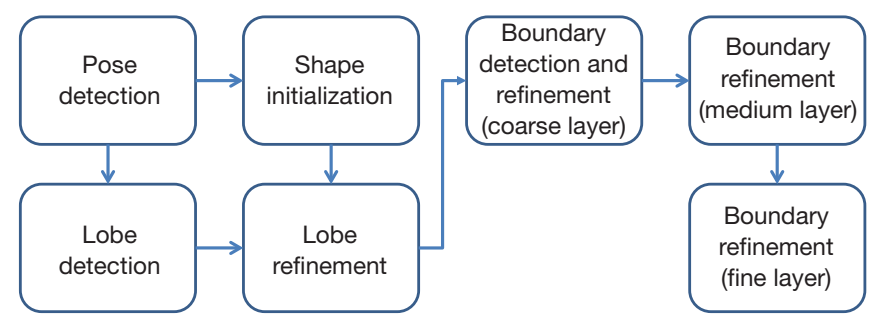

Figure 2 Flowchart and components of the liver segmentation system.

was applied whereas for learning the marginal probabilities [i.e. $\operatorname{Pr}(\mathrm{p} \mid \mathrm{vol}), \operatorname{Pr}(\theta \mid \mathrm{p}, \mathrm{vol})$, and $\operatorname{Pr}(\mathrm{s} \mid \theta, \mathrm{p}, \mathrm{vol})]$, the probabilistic boosting tree (PBT) was used.

For boundary detection we learned $\operatorname{Pr}(\mathrm{bdry} \mid \mathrm{q}$, voll) using PBT and steerable features and in addition, the spherical coordinates of mesh points were included as features. The heterogeneity of texture pattern along liver boundaries imposed the use of patch-dependent boundary classifiers. To this end, we decomposed a liver surface to five patches: liver-lung, liver-heart, liver-kidney, liver-tissue, and livermisc.

In about $10 \%$ of cases, an incorrect segmentation was followed by manual adjustment by an experienced radiologist (H.M.) with 30 years' experience in liver imaging.

\section{Histopathology and surgery}

Classification of the liver parenchyma depending on the degree of fibrosis was performed by the ISHAKclassification (19). Moreover, the Model for end-stage liver disease (MELD) score was calculated by incorporation of the 3 variables: total bilirubin, creatinine, and INR (20). Liver weight was calculated on exsanguinated and already formalin fixed liver grafts.

Liver explantation or hemi-hepatectomy was performed according to generally used technical requirements.

The surgical procedure in the particular case of the 4 patients presenting with polycystic liver disease was performed as follows: sharp severing of the ligamentum teres, falciformis, triangularis right and left as well as the omentum minus with subsequent mobilization of the left and right lobes of the liver; cutting of the cystic duct and the cystic artery. Isolation of the hepatic artery dextra and sinistra and cutting of the same below the hilar plate and free preparation of the same up to the level of the bifurcation of the hepatic artery communis with the gastroduodenal artery; dissection of the portal vein from periportal lymphatic tissue; dissection of the retrohepatic inferior caval vein from the retroperitoneum.

\section{Statistical analysis}

All nominal scaled variables were given as mean \pm standard deviation. We calculated the density of the explanted livers by dividing their histopathological measured weight by their calculated volume $(\mathrm{g} / \mathrm{mL})$. We separated the livers into three independent groups depending on their histopathological proven degree of fibrosis (21). After verification of non-Gaussian distribution of every parameter by the Shapiro-Wilk test, we opted for a non-parametric test (Kruskal-Wallis-H test or Mann-Whitney-U test) to analyze differences between the independent samples. Posthoc and Dunn-Bonferroni tests were used to differentiate the groups. A Pearson-test was used for the correlation between weight and measured liver volume. Regression analysis was diagrammed on a scatterplot. With regards to potential errors with respect to liver density due to differences caused by embedded HCC in patients who were screened for HCC we separately calculated the total tumor volume using the formula for spheric volume: $\mathrm{V}=\frac{4}{3} \times \pi \times r^{3}$ and expressed it as ratio to the entire liver volume.

All statistical analyses and graphics were performed by using SPSS version 27.0 (IBM, Stanford). A two tailed P value of less than 0.05 was considered to indicate statistical significance.

\section{Results}

\section{Characteristics}

In total we included 114 patients who had a CT-scan previous to their liver transplantation. About 90 (78.9\%) patients suffered from pathologies resulting in liver cirrhosis (see Table 1). Median MELD scores did not differ 
Table 1 Patient characteristics

\begin{tabular}{lc}
\hline Characteristics & Data, $\mathrm{n}=114$ \\
\hline Age (years) & $46 \pm 20$ \\
Sex & $75(65.8 \%)$ \\
Male & $39(34.2 \%)$ \\
Female & \\
Liver transplantation & $97(85.1 \%)$ \\
Full liver transplantation & $9(7.9 \%)$ \\
Left split liver transplantation & $8(7.0 \%)$ \\
Right split liver transplantation & \\
Initial pathology & $35(30.7 \%)$ \\
Toxic (alcohol) & $41(35.9 \%)$ \\
Infectious (viral) & $4(3.5 \%)$ \\
Metabolic disorders & $1(0.9 \%)$ \\
Chronic stasis (cor pulmonale) & $9(7.9 \%)$ \\
Cryptogenic & $3(2.6 \%)$ \\
Primary tumor & $8(7.0 \%)$ \\
Secondary tumor & $13(11.4 \%)$ \\
Other causes &
\end{tabular}

statistically significantly among the different cirrhosis inducing etiologies (toxic, infectious, metabolic, chronic or cryptogenic) ranging between 19 and $21(\mathrm{P}>0.05)$. A total of 32 patients presented with subsequent hepatocellular carcinoma. Of them, 26 were initially inside Milan whereas 6 were outside Milan criteria. These 6 patients were successfully down staged by means of transarterial hepatic chemoembolization (TACE). The HCC-to-liver volume ratios ranged between $1.6 \%$ for cases inside Milan and 3.4\% in patients classified out of Milan.

\section{Polycystic liver analysis}

The 4 patients suffering from polycystic liver disorder were analyzed separately due to the particular consistency of these livers (see Table 2 and Figure 3). Their ages ranged between 55 and 62 years. All of them were female.

\section{Density depending on ISHAK-Scores}

Patients with an Ishak-stage of 6 had a significant higher liver parenchyma density $(1.06 \pm 0.20 \mathrm{~g} / \mathrm{mL})$ compared
Table 2 Polycystic liver analysis

\begin{tabular}{lccc}
\hline Patient & $\begin{array}{c}\text { Liver volume } \\
(\mathrm{mL})\end{array}$ & $\begin{array}{c}\text { Histopathological } \\
\text { weight }(\mathrm{g})\end{array}$ & $\begin{array}{c}\text { Density } \\
(\mathrm{g} / \mathrm{mL})\end{array}$ \\
\hline 1 & 2,931 & 2,664 & 0.91 \\
2 & 5,397 & 4,573 & 0.85 \\
3 & 5,318 & 3,975 & 0.75 \\
4 & 5,862 & 4,279 & 0.73 \\
\hline
\end{tabular}
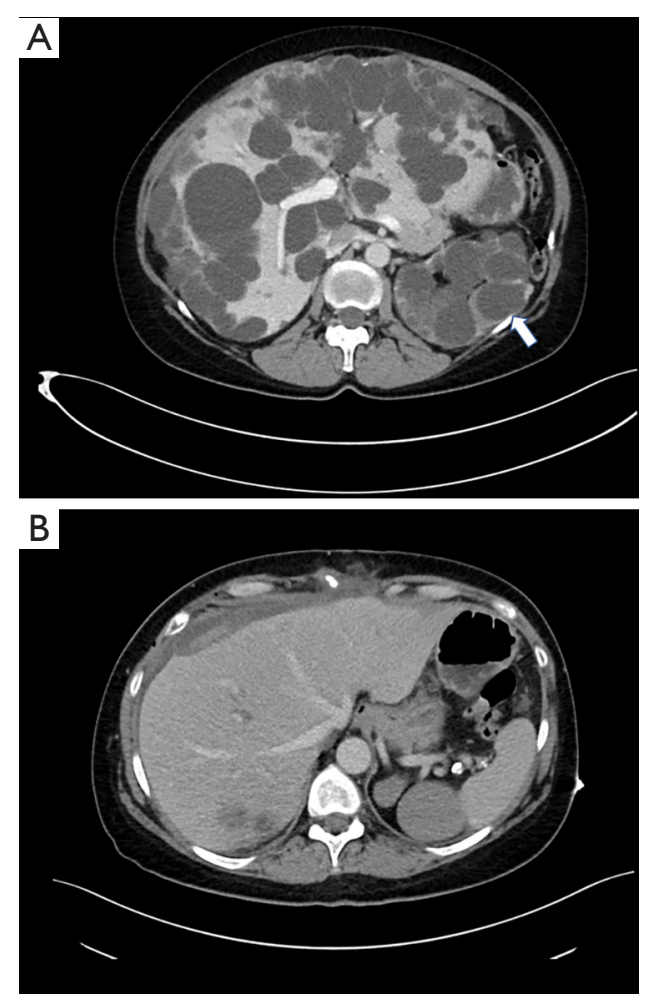

Figure 3 A 55-year-old patient with polycystic liver and kidney (white arrow) disease (A) before and (B) after liver transplantation.

to those with Ishak-stage of $0-3(0.92 \pm 0.22)$ and $4-5$ $(0.98 \pm 0.28)$ (see Table 3).

All three subgroups showed an excellent Pearson correlation $(\mathrm{P}<0.000)$. Linear regression analysis is displayed in the scatterplots (Figure 4), demonstrating a higher gradient with increasing ISHAK-Score (ISHAK 0-3: 0.77, ISHAK 4-5: 0.87, ISHAK 6: 0.97).

Thirty-five patients suffered from liver fibrosis secondary to toxic mechanisms (alcoholism, drug abuse). Forty-one patients had liver fibrosis secondary to infectious diseases (viral genesis in all of the cases). Patients with liver fibrosis 
Table 3 Density depending on ISHAK-stages

\begin{tabular}{|c|c|c|c|c|}
\hline Variable & ISHAK 0-3 (n=32) & ISHAK 4-5 $(n=18)$ & ISHAK $6(n=60)$ & $P$ value \\
\hline Weight (g) & $1,624 \pm 999$ & $1,082 \pm 669$ & $1,346 \pm 559$ & $0.048^{*}$ \\
\hline Density (g/mL) & $0.92 \pm 0.22$ & $0.98 \pm 0.28$ & $1.06 \pm 0.20$ & $0.002^{*}$ \\
\hline Delay between CT-scan and transplantation (days) & $17 \pm 20$ & $40 \pm 33$ & $23 \pm 25$ & $0.051^{*}$ \\
\hline
\end{tabular}

${ }^{\star}$ Kruskal-Wallis H-test.
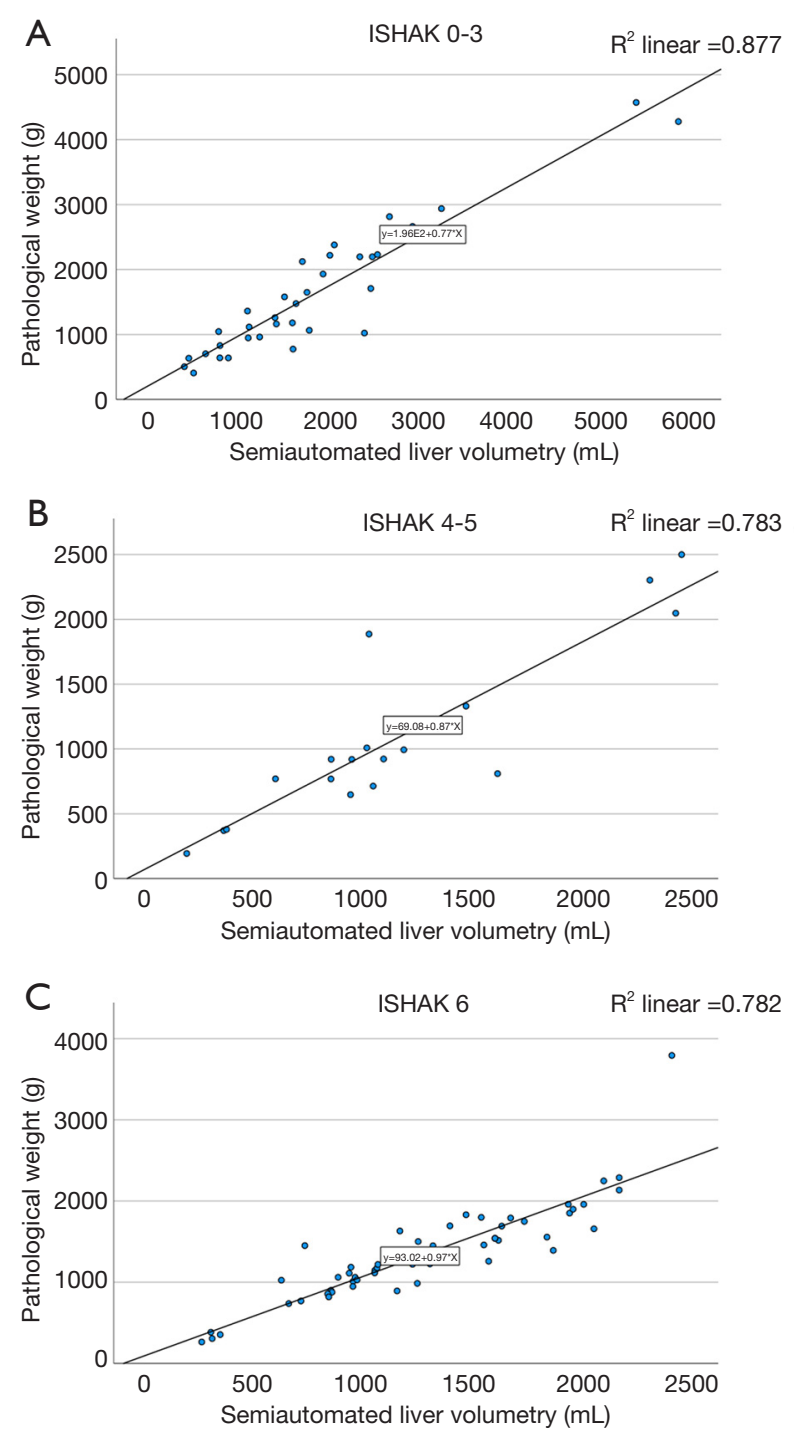

Figure 4 Linear regression analysis depending on ISHAK-Score. induced by toxic mechanisms had significant higher liver parenchyma density compared to those with inflammatory liver pathology $(\mathrm{P}<0.05)$ (see Table 4).

\section{Discussion}

The intention of this study was to find out if the coefficients used for conversion of ex vivo measured liver weight into in vivo liver volume and vice versa significantly differ throughout the pathologic liver fibrosis classes defined by the Ishak classification. Expectedly, our results show a clear trend towards higher liver parenchymal density (coefficient factor) with increasing Ishak stage, reaching statistical significance in each class of our cohort, as well as additionally for the subgroup of patients with cystic liver disease which were analyzed separately.

Of note, liver weights were calculated in explanted livers which were exsanguinated, already formalin fixed so that these results are not perfectly comparable with in-vivo measurements, hence applicable only in this given clinical setting. However, the role of conversion coefficients is relevant, e.g., for concluding about the initial organ volume.

The risk of transplant rejection in the case of a liver that is too large or too small should not be underestimated. Therefore, several more or less promising attempts have been made to estimate the metabolic differences between recipient and donor as far as possible before transplantation e.g., graft weight to recipient weight ratio (22) or donor height to recipient height ratio (5), always with the final intention of reducing the rate of "small-for-size syndrome" or "large-for-size syndrome" $(4,23)$. Previous reports using freehand computed tomographic volume quantification for assessment of the total liver volume have compared their 
Table 4 Density depending on underlying causes of chronic liver disease

\begin{tabular}{|c|c|c|c|}
\hline Variable & Toxic $(n=35)$ & Infectious $(n=41)$ & $P$ value \\
\hline Weight (g) & $1,365 \pm 494$ & $1,280 \pm 469$ & $0.518^{*}$ \\
\hline Density (g/mL) & $1.08 \pm 0.26$ & $0.97 \pm 0.18$ & $0.025^{\star}$ \\
\hline Delay between CT-Scan and transplantation (days) & $26 \pm 28$ & $23 \pm 26$ & $0.851^{*}$ \\
\hline
\end{tabular}

*Mann-Whitney-U-test.

results with the weights of explanted organs in cirrhotic patients and found the liver density to be about $1.1 \mathrm{~kg} / \mathrm{L}$ (24). In this paper, the authors used by comparison with our study three-phase CECT-image data, thick-slices, excluding the main hepatic vessels from the final liver volume quantification. The exclusion of the larger liver vessels might explain to some extent the slight difference in liver density compared to our data. Satou $e t$ al. have shown that after back-table surgery has been completed, the weight of the explanted liver drops by up to $10 \%$ which would largely explain these differences (25). In normal livers, the specific gravity of a cirrhotic liver was demonstrated to be significantly lower $(1 \mathrm{mg} / \mathrm{L})(16)$. In a study conducted by Goumard et al. the coefficient factor for assessment of liver density was found in a similar range as in our study (26). The authors indicated that liver density and liver volume are changing with advancing cirrhosis and that differences in liver density compared with those of patients with e.g., NASH proved significant, the latter proving significantly lower which can be easily explained by fat deposition which exhibits lower density. Liver volume assessment was performed manually in their study by excluding the large central hepatic vessels. Yoneyama et al. found the liver density of cirrhotic livers to be also within similar ranges (mean, $1 \mathrm{~g} / 1 \mathrm{~mL}$ ) showing, however, significantly lower values $(0.85 \mathrm{~kg} / \mathrm{L})$ in non-cirrhotic patients (16). Interestingly, Sonnemans et al. found higher density values in normal livers $(1.13 \mathrm{~g} / \mathrm{mL})$ compared to our cirrhotic patients, demonstrating concomitantly, that these values significantly declined in patients with other pathologies like fatty liver and in particular in such with cardiovascular problems and secondary hepatic stasis causing changes in the liver parenchymal consistency by increased blood content (18). Hence, the linear relationship between liver volume and liver density as described by Van Thiel et al. could be reproduced in most studies including ours (11). Nevertheless, differences in the calculation of liver density may occur and are related either to technical issues (accuracy of liver volumetry, examinational protocol), hepatic particularities (unusual form, surface, collateral vessels, gallbladder, the presence of hepatic tumors, cysts, attached ligaments) or to surgical causes like intraoperative drainage of liquids from the liver. In our study, automated volumetry results were additionally controlled by a senior radiologist who in case of mismeasurement manually corrected the volumetric assessment. Moreover, we analyzed in our study also differences in liver volume and density between toxic and infectious chronic liver diseases which, however, proved insignificant. Hence, the assumption was that if the quantified liver volume would be the standard of reference and the exsanguinated explanted livers would all be weighted in a standardized fashion and the degree of liver fibrosis scored according to the Ishak classification, then the liver densities (coefficient factors) could be accurately assessed.

To our knowledge, this study is the first to report about differences in liver density throughout different stages of chronic liver disease as assessed histologically based on the Ishak stage as well as to address the expected conversion coefficient in case of ex vivo exsanguinated livers.

Our study has some limitations. First, the different underlying diseases and their stages made the cohort heterogeneous in these terms. However, this reflects the everyday situation where every patient is finally particular in these terms. Second, individual factors with potential impact on the volume quantification like the hydration grade, postoperative liver fixation with formalin, cardiocirculatory status, or accompanying disorders like steatosis have not been additionally considered in this study. Third, the semiautomated liver volumetry is not a gold-standard, but supplemented by the expertise of a senior radiologist supervising the results should be a guarantor for accurate measurements. Fourth, in case of polycystic livers, technical particularities like difficulties in the organ mobilization, intra-operative need for cyst transection due to adhesions could affect the entire liver volume measurements. This, however, was not the case in our series. Fifth, some patients 
also had hepatocellular carcinomas diagnosed in the pre-operative setting. The HCC-to-liver volume ratios proved very low in both patient subgroups (inside and outside Milan criteria), so that the potential impact of the differences in the density of tumor to liver are not expected to affect the final results.

In conclusion, our results yielded significant differences between the density coefficients calculated along with the Ishak stage and also for the subgroup with cystic liver disease in exsanguinated explanted livers. This helps to reduce weight mismatches preoperatively and ultimately possibly minimize graft rejections.

\section{Acknowledgments}

Funding: None.

\section{Footnote}

Conflicts of Interest: All authors have completed the ICMJE uniform disclosure form (available at https://dx.doi. org/10.21037/qims-21-299). The authors have no conflicts of interest to declare.

Ethical Statement: The authors are accountable for all aspects of the work in ensuring that questions related to the accuracy or integrity of any part of the work are appropriately investigated and resolved. The study was conducted in accordance with the Declaration of Helsinki (as revised in 2013). This retrospective data evaluation was approved by the institutional review board which was assigned the approval number $841 / 2020 \mathrm{BO} 2$. Verbal and written informed consent was waived due to the retrospective nature of the study.

Open Access Statement: This is an Open Access article distributed in accordance with the Creative Commons Attribution-NonCommercial-NoDerivs 4.0 International License (CC BY-NC-ND 4.0), which permits the noncommercial replication and distribution of the article with the strict proviso that no changes or edits are made and the original work is properly cited (including links to both the formal publication through the relevant DOI and the license). See: https://creativecommons.org/licenses/by-nc-nd/4.0/.

\section{References}

1. Lemke AJ, Hosten N, Neumann K, Müller B, Neuhaus
P, Felix R, Langer R. CT volumetry of the liver before transplantation. Rofo 1997;166:18-23.

2. Nakayama Y, Li Q, Katsuragawa S, Ikeda R, Hiai Y, Awai K, Kusunoki S, Yamashita Y, Okajima H, Inomata Y, Doi K. Automated hepatic volumetry for living related liver transplantation at multisection CT. Radiology 2006;240:743-8.

3. Emond JC, Renz JF, Ferrell LD, Rosenthal P, Lim RC, Roberts JP, Lake JR, Ascher NL. Functional analysis of grafts from living donors. Implications for the treatment of older recipients. Ann Surg 1996;224:544-52; discussion 552-4.

4. Kiuchi T, Kasahara M, Uryuhara K, Inomata Y, Uemoto S, Asonuma K, Egawa H, Fujita S, Hayashi M, Tanaka $\mathrm{K}$. Impact of graft size mismatching on graft prognosis in liver transplantation from living donors. Transplantation 1999;67:321-7.

5. Kesseli SJ, Samoylova ML, Yerxa J, Moore CB, Cerullo M, Gao Q, Abraham N, Patel YA, McElroy LM, Vikraman D, Barbas AS. Donor-Recipient Height Mismatch Is Associated With Decreased Survival in Pediatric-to-Adult Liver Transplant Recipients. Liver Transpl 2021;27:425-33.

6. Choukèr A, Martignoni A, Dugas M, Eisenmenger W, Schauer R, Kaufmann I, Schelling G, Löhe F, Jauch $\mathrm{KW}$, Peter K, Thiel M. Estimation of liver size for liver transplantation: the impact of age and gender. Liver Transpl 2004;10:678-85.

7. Lim MC, Tan CH, Cai J, Zheng J, Kow AW. CT volumetry of the liver: where does it stand in clinical practice? Clin Radiol 2014;69:887-95.

8. Gotra A, Sivakumaran L, Chartrand G, Vu KN, Vandenbroucke-Menu F, Kauffmann C, Kadoury S, Gallix B, de Guise JA, Tang A. Liver segmentation: indications, techniques and future directions. Insights Imaging 2017;8:377-92.

9. Norajitra T, Maier-Hein KH. 3D Statistical Shape Models Incorporating Landmark-Wise Random Regression Forests for Omni-Directional Landmark Detection. IEEE Trans Med Imaging 2017;36:155-68.

10. Campadelli P, Casiraghi E, Esposito A. Liver segmentation from computed tomography scans: a survey and a new algorithm. Artif Intell Med 2009;45:185-96.

11. Van Thiel DH, Hagler NG, Schade RR, Skolnick ML, Heyl AP, Rosenblum E, Gavaler JS, Penkrot RJ. In vivo hepatic volume determination using sonography and computed tomography. Validation and a comparison of the two techniques. Gastroenterology 1985;88:1812-7. 
12. Goja S, Yadav SK, Yadav A, Piplani T, Rastogi A, Bhangui P, Saigal S, Soin AS. Accuracy of preoperative CT liver volumetry in living donor hepatectomy and its clinical implications. Hepatobiliary Surg Nutr 2018;7:167-74.

13. Bai R, Yu X, Wang D, Lv J, Xu G, Lai X. The densities of visceral organs and the extent of pathologic changes. Am J Forensic Med Pathol 2009;30:148-51.

14. Radtke A, Nadalin S, Sotiropoulos GC, Molmenti EP, Schroeder T, Valentin-Gamazo C, Lang H, Bockhorn M, Peitgen HO, Broelsch CE, Malagó M. Computerassisted operative planning in adult living donor liver transplantation: a new way to resolve the dilemma of the middle hepatic vein. World J Surg 2007;31:175-85.

15. Rockey DC, Caldwell SH, Goodman ZD, Nelson RC, Smith AD; American Association for the Study of Liver Diseases. Liver biopsy. Hepatology 2009;49:1017-44.

16. Yoneyama T, Asonuma K, Okajima H, Lee KJ, Yamamoto H, Takeichi T, Nakayama Y, Inomata Y. Coefficient factor for graft weight estimation from preoperative computed tomography volumetry in living donor liver transplantation. Liver Transpl 2011;17:369-72.

17. Yu HC, You H, Lee H, Jin ZW, Moon JI, Cho BH. Estimation of standard liver volume for liver transplantation in the Korean population. Liver Transpl 2004; 10:779-83.

18. Sonnemans LJ, Hol JC, Monshouwer R, Prokop M, Klein WM. Correlation Between Liver Volumetric Computed Tomography Results and Measured Liver Weight: A Tool for Preoperative Planning of Liver Transplant. Exp Clin Transplant 2016;14:72-8.

19. Goodman ZD. Grading and staging systems for inflammation and fibrosis in chronic liver diseases. J Hepatol 2007;47:598-607.

20. Peng Y, Qi X, Guo X. Child-Pugh Versus MELD Score for the Assessment of Prognosis in Liver Cirrhosis: A Systematic Review and Meta-Analysis of Observational Studies. Medicine (Baltimore) 2016;95:e2877.

21. Everhart JE, Wright EC, Goodman ZD, Dienstag JL, Hoefs JC, Kleiner DE, Ghany MG, Mills AS, Nash SR, Govindarajan S, Rogers TE, Greenson JK, Brunt EM, Bonkovsky HL, Morishima C, Litman HJ; HALT-C Trial Group. Prognostic value of Ishak fibrosis stage: findings from the hepatitis $\mathrm{C}$ antiviral long-term treatment against cirrhosis trial. Hepatology 2010;51:585-94.

22. Hill MJ, Hughes M, Jie T, Cohen M, Lake J, Payne WD, Humar A. Graft weight/recipient weight ratio: how well does it predict outcome after partial liver transplants? Liver Transpl 2009;15:1056-62.

23. Jeong SY, Lee J, Kim KW, Jang JK, Kwon HJ, Song GW, Lee SG. Estimation of the Right Posterior Section Volume in Live Liver Donors: Semiautomated CT Volumetry Using Portal Vein Segmentation. Acad Radiol 2020;27:210-8.

24. Haberal KM, Kural Rahatlı F, Turnaoğlu H, Özgün G, Coşkun M. Use of Computed Tomography Volumetry to Assess Liver Weight in Patients With Cirrhosis During Evaluation Before Living-Donor Liver Transplant. Exp Clin Transplant 2021;19:149-53.

25. Satou S, Sugawara Y, Tamura S, Yamashiki N, Kaneko J, Aoki T, Hasegawa K, Beck Y, Makuuchi M, Kokudo N. Discrepancy between estimated and actual weight of partial liver graft from living donors. J Hepatobiliary Pancreat Sci 2011;18:586-91.

26. Goumard C, Perdigao F, Cazejust J, Zalinski S, Soubrane $\mathrm{O}$, Scatton O. Is computed tomography volumetric assessment of the liver reliable in patients with cirrhosis? HPB (Oxford) 2014;16:188-94.
Cite this article as: Hagen F, Mair A, Bösmüller H, Horger M. Correlation between liver volume and liver weight in a cohort with chronic liver disease: a semiautomated CT-volumetry study. Quant Imaging Med Surg 2022;12(1):376-383. doi: 10.21037/qims-21-299 